\title{
Prevention of duodenal ulcers in the rat using a combination of ranitidine and sucralphate in subtherapeutic doses
}

\author{
S BANK, H ZIMMERMAN, C SMOLOW, AND VICTORIA KRANZ \\ From the Division of Gastroenterology, Department of Medicine, Long Island Jewish-Hillside Medical \\ Center, New Hyde Park, New York, and State University of New York, Stony Brook, New York, USA
}

SUMMARY This study investigated whether ulcer prevention would be greater with the combined use of an acid-inhibiting agent, ranitidine, given together with a mucosal-protective agent, sucralphate. Duodenal ulcers were induced in rats with the secretagogues pentagastrin and bethanechol. Subtherapeutic doses of ranitidine $(5 \mathrm{mg} / \mathrm{kg} / 6$ hours $)$ and sucralphate $(50 \mathrm{mg} / 6$ hour) yielded an ulcer index of 4.0 and 4.1 respectively, not significantly different from the control (untreated) ulcer index of $4 \cdot 3$. Therapeutic doses of ranitidine $(20 \mathrm{mg} / \mathrm{kg})$ and sucralphate (200 mg/animal) gave an ulcer index of 0.4 and 0.5 respectively. Subtherapeutic doses of ranitidine and sucralphate given in combination yielded an ulcer index of 0.7 . Thus, subtherapeutic doses of ranitidine and sucralphate given in combination had a synergistic effect equal to therapeutic doses of each of these drugs given alone. The therapeutic implications of combined acid inhibiting drugs with mucosal protective drugs is discussed.

The time honoured equation of ulcer disease acidpepsin aggression $v s$ mucosal resistance remains the mainstay of the therapeutic approach to ulcer disease. $\mathrm{H}_{2}$ histamine receptor antagonists and the mucosa-protective, or cytoprotective agents have been shown to promote ulcer healing in man. They also prevent ulcer formation by a large variety of ulcer-inducing techniques in animals. ${ }^{1-3}$ There have been few investigations whether ulcer prevention would be greater with the combined use of an acid-inhibiting agent with a mucosal-protective agent. The effect of ranitidine, a histamine $\mathrm{H}_{2}$ receptor antagonist and sucralphate, a mucosalprotective agent, were investigated alone to establish therapeutic and subtherapeutic levels in an ulcer model; the combination of these drugs at subtherapeutic levels was then studied in the same animal model.

\section{Methods}

\section{ANIMALS}

Seventy six female Wistar rats weighing between Address for correspondence: Simmy Bank, MD. Chief, Div of Gastroenterology, Long Island Jewish-Hillside Med Ctr, New Hyde Park, NY 11042, USA.

Received for publication 27 July 1984
170-200 $\mathrm{g}$ were fasted for 24 hours before the experiment. Duodenal ulceration was induced by a method previously described. ${ }^{4}$ Briefiy, this consisted of the subcutaneous infusion of pentagastrin 2.5 $\mu \mathrm{g} / \mathrm{kg} / \mathrm{min}$, and bethanechol $12 \mu \mathrm{g} / \mathrm{kg} / \mathrm{min}$, for 24 hours through a needle inserted between the shoulder blades. The rats were allowed reasonable mobility in cages $25 \times 5 \times 5 \mathrm{~cm}$. Five sets of experiments were done.

\section{Pilot study}

Six rats were used to test the stress related ulcerogenic effect of the experimental system. These animals received a 24 hour subcutaneous infusion of saline in place of pentagastrin or bethanechol and received no oral medication during the time they were placed in the restraining cages.

\section{Control group}

Nine rats received 24 hour infusion of pentagastrin and bethanechol and were given saline via intragastric feeding tube at the start of the infusion and at three subsequent occasions six hours apart. This tested the efficacy of the ulcerogenic protocol. 


\section{Sucralphate group}

Twenty seven rats were divided into three groups of nine. All the groups received sucralphate at the start of the infusion and every six hours thereafter. Sucralphate was crushed and given as a suspension in saline via an intragastric feeding tube. Group one received $50 \mathrm{mg}$ per dose as a $10 \%$ suspension. Group two received $100 \mathrm{mg}$ per dose as a $10 \%$ suspension. Group three received $200 \mathrm{mg}$ per dose as a $20 \%$ suspension $(20 \%$ suspension was used to decrease the total volume administered).

\section{Ranitidine group}

Twenty seven rats were divided into three groups of nine. Each of these groups received ranitidine at the start of the infusion and every six hours thereafter via an intragastric feeding tube. The first group received ranitidine at a dose of $5 \mathrm{mg} / \mathrm{kg}$ as a $0.25 \%$ suspension in saline. Second group received $10 \mathrm{mg} / \mathrm{kg}$ as $0.5 \%$ suspension and the third received $20 \mathrm{mg} / \mathrm{kg}$ as a $1 \%$ suspension.

\section{Sucralphate and ranitidine group}

Nine rats received $50 \mathrm{mg}$ of sucralphate as a $10 \%$ suspension at the start of the infusion and every six hours thereafter. In addition, ranitidine was given at $5 \mathrm{mg} / \mathrm{kg}$ as a $0.25 \%$ suspension in saline one hour after each of the sucralphate doses. Both were given by intragastric feeding tubes.

At the end of the 24 hours the rats were killed with intracardiac pentabarbitol and the stomach and duodenum dissected; the duodenal mucosa was examined with a $10 \times$ magnifying hand lens by three observers (of which one (SB) was blinded) for the presence of ulceration. The severity of the ulcer was scored as follows: $0=$ no ulcer, $1=$ superficial erosions, $2=$ black based ulcer, $3=$ penetrating, or perforating ulcer. The ulcer index was calculated by the following formula: Index=mean severity $+(\text { incidence } \times 2 \text {. })^{5}$ The severity of ulceration was averaged between the three observers, there was little difference between observers as the grading was distinct. The ulcer index scores were analysed by the two tailed Mann Whitney test. The gastric $\mathrm{pH}$ was estimated with a mini-surface electrode (Beckman pH meter, model 3500) but formal acid and pepsin studies were not done as this was not the intention of this study.

\section{Results}

\section{Pilot study}

No ulcers, or erosions were found in any of the six rats used in the pilot study. These results verify that the drug free experimental protocol was itself not ulcerogenic.

\section{Control group}

All nine control rats developed duodenal ulcers of marked severity, with an ulcer index of $4 \cdot 3$. The $\mathrm{pH}$ range was $1 \cdot 2-1 \cdot 7$.

\section{Sucralphate group}

The effect of varying doses of sucralphate on the incidence of ulcers and ulcer index is shown in Figure 1 . The $50 \mathrm{mg}$ dose was almost ineffective in preventing ulceration, eight of the nine rats having severe ulcers, not significantly different from controls $(p<0 \cdot 1)$ with a mean ulcer index of $4 \cdot 1$. The gastric mucosa had a $\mathrm{pH}$ range of 1.0-1.7.

In contrast with the $50 \mathrm{mg}$ dose, the $100 \mathrm{mg}$, and $200 \mathrm{mg}$ doses had an increasing protective effect on ulcer formation.

Only one of nine animals had an erosion after the $200 \mathrm{mg}$ dose. This was significantly different from controls $(\mathrm{p}<0.02)$. The mucosa had a $\mathrm{pH}$ range of $1 \cdot 0-3 \cdot 0$.

\section{Ranitidine group}

All rats at the $5 \mathrm{mg} / \mathrm{kg}$ dose developed ulceration (Fig. 2) with the mean ulcer index of $4 \cdot 0$, not significantly different $(p<0 \cdot 1)$ from the control group. The mucosal $\mathrm{pH}$ with the $5 \mathrm{mg} / \mathrm{kg}$ dose was virtually unchanged from the control group (with a $\mathrm{pH}$ range of $1 \cdot 2-1 \cdot 7)$.

In contrast with the $5 \mathrm{mg} / \mathrm{kg}$ dose, the 10 , and 20 $\mathrm{mg} / \mathrm{kg}$ doses had an increasingly inhibitory effect on ulcer formation. Only two animals had ulceration after the $20 \mathrm{mg} / \mathrm{kg}$ dose, with an ulcer index of $0 \cdot 4$.

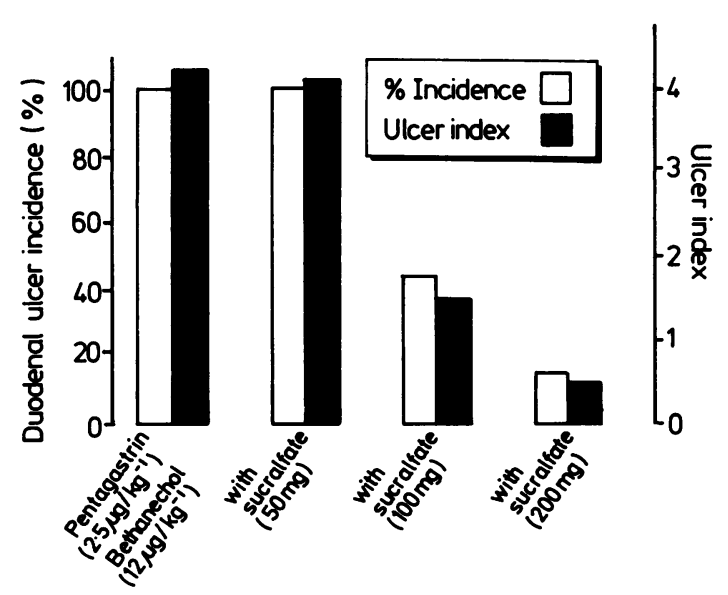

Fig. 1 Effect of sucralphate $50 \mathrm{mg}, 100 \mathrm{mg}$, and 200 $\mathrm{mg}$ four times a day on the incidence and ulcer index of secretagogue-induced duodenal ulcer. (Sucralphate vs control, $200 \mathrm{mg}$ and $100 \mathrm{mg} \mathrm{p}<0.001$ and $50 \mathrm{mg}=\mathrm{NS}$ ). 


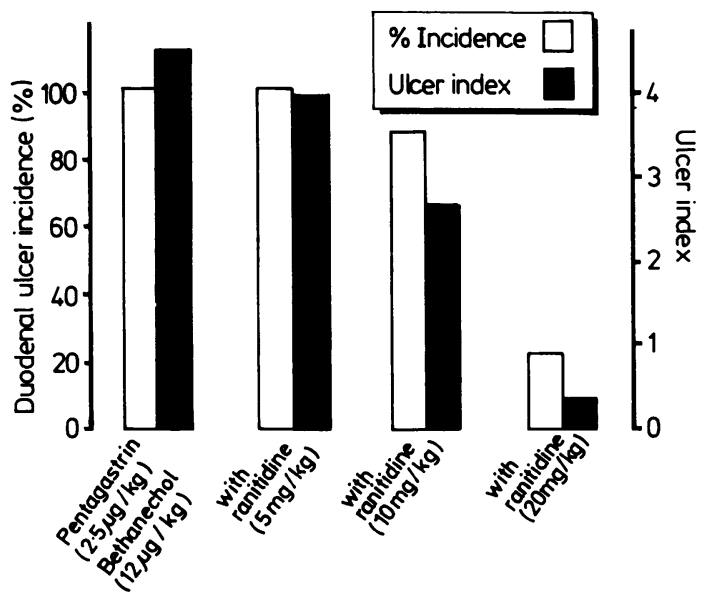

Fig. 2 Effect of ranitidine $5 \mathrm{mg} / \mathrm{kg}, 10 \mathrm{mg} / \mathrm{kg}$ and 20 $m g / k g$ four times a day on the incidence and ulcer index of secretagogue-induced duodenal ulcer. (Ranitidine vs control, $20 \mathrm{mg} / \mathrm{kg} \mathrm{p}<0.00110 \mathrm{mg} / \mathrm{kg} \mathrm{p}<0.01$, and 5 $m g=N S$ ).

This was significantly different $(p<0.002)$ from control. The gastric mucosa had a $\mathrm{pH}$ range of 3-7.

\section{Sucralphate and ranitidine group}

Doses of $50 \mathrm{mg}$ sulcralphate and $5 \mathrm{mg} / \mathrm{kg}$ ranitidine were subtherapeutic, in that they were associated with near $100 \%$ ulcer incidence and an ulcer index not significantly different from controls. When given in combination, the incidence of ulcer was decreased to $22 \%$ (two of nine rats), with an ulcer index of 0.7 . This was significantly less than controls $(p<0.002)$. In fact, of the two animals showing ulceration the latter were no more than erosions. The data are presented in Figure 3. The mucosal $\mathrm{pH}$ with this combination of drugs was only slightly higher, $\mathrm{pH}$ range $1 \cdot 9-3 \cdot 1$, when compared with controls, or when the drugs were given individually.

\section{Discussion}

This study showed that histamine $\mathrm{H}_{2}$ antagonists and sucralphate prevent the formation of pentagastrin-bethanechol induced duodenal ulceration in the rat, and that the protective effect was dose dependent. Virtually complete protection from ulceration was recorded when the drugs were given together in doses that failed to prevent ulcer formation when they were given alone. Thus, 'subtherapeutic' doses given in combination had a

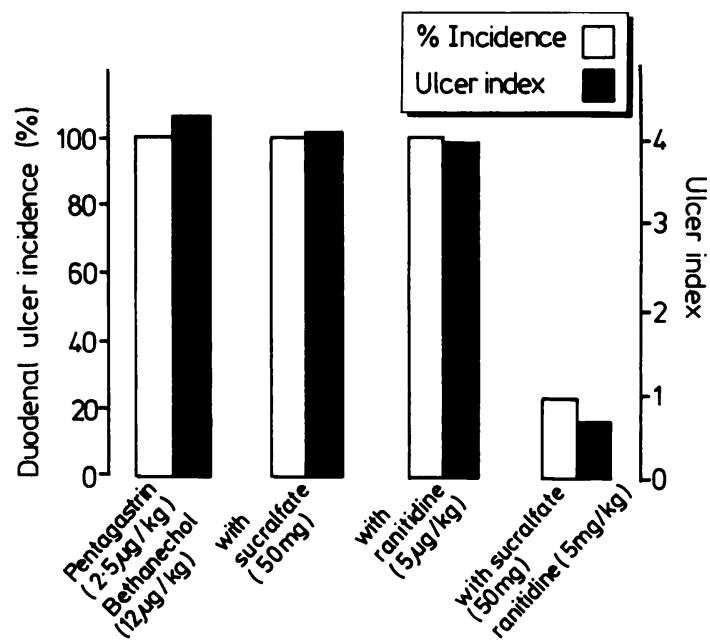

Fig. 3 Effect of subtherapeutic doses - that is $50 \mathrm{mg}$ sucralphate four times a day and $5 \mathrm{mg} / \mathrm{kg}$ ranitidine four times a day, on the incidence and ulcer index of secretagogue-induced duodenal ulcer. (Pentagastrin/ bethanechol vs sucralphate NS; vs combined sucralphate/ranitidine $p<0 \cdot 001$.)

synergistic protective effect equal to therapeutic doses of each of the drugs when they were given separately.

The mechanism of ulcer prevention with the two drugs differs. Ranitidine protects the duodenum from the acid load induced by pentagastrin and bethanechol by inhibiting acid output. ${ }^{6}$ Sucralphate protects the mucosa by forming a mucosal protective layer, or sealing micro-ulcers by binding with juxtamucosal, or ulcer proteins; $;^{37}$ although the data $^{7}$ refer to gastric mucosa, and not to duodenal mucosa as in the present study. Sucralphate has little effect on intragastric $\mathrm{pH}$. It is therefore reasonable to conclude that the drugs act at the two ends of the ulcer equation, ranitidine on the aggressive factors and sucralphate on the defensive side. Although both drugs affect peptic activity, ranitidine by raising the intragastric $\mathrm{pH}$ and sucralphate by a binding to pepsin, the inactivation of peptic activity was ineffective in preventing ulcer formation when the drugs were given alone at the subtherapeutic doses. The mechanism of the synergism is unclear as the study was not designed to include acid-pepsin measurements.

Whether the findings in this experimental study bear any relevance to therapy in man is uncertain. This study, however, appears to present the first experimental evidence of the possible beneficial effect of combining acid-inhibitory and mucosal protective agents. At present there is no good 
evidence to show that combining such agents in therapeutic doses increases ulcer healing or preventive potential above that of the single agents in established therapeutic doses. As the toxicity and adverse effects of the many ulcer preparations presently being used are clearly related to potency and dose, ${ }^{8}$ the combined use of subtherapeutic doses may be of therapeutic importance.

\section{References}

1 Joffe SN, Gaskin RJ, Barros D, Baron JH. Prevention of secretagogue induced ulcers in the rat. Gastroenterology 1976; 70: 751-2.

2 Kaplan E, Barbezat GO, Millner G. Studies with metiamide in the prevention of duodenal ulceration in the rat. Gastroenterology 1976; 70: 475-6.

3 Smolow CR, Bank S, Ackert G, Anfang C, Kranz V. Prevention of duodenal ulcers in the rat by sucralfate. Scand J Gastroenterol 1983; suppl. 83: 15-6.

4 Robert A, Stout TJ, Dale JE. Production by secretagogues of duodenal ulcers in the rat. Gastroenterology 1970; 59: 95-102.

5 Szabo S. Animal model of human disease, duodenal ulcer disease. Am J Pathol 1978; 93: 273-6.

6 Konturek SJ, Obtulowicz W, Kwiecien W, Kopp B, Oleksy J. Dynamics of gastric acid inhibition by ranitidine in duodenal ulcer patients. Digestion 1981; 22: 119-25.

7 Harrington SJ, Schlegel JF, Code CF. The protective effect of sucralfate on the gastic mucosa in rats. $J$ Clin Gastrol 1981; 3: 129-34.

8 Simon B, Muller P, Dammann HG, Kommerell B. Adverse effects of cimetidine and safety profile of ranitidine. In Miscewicz JJ, Wormsley $\mathrm{KG}$ eds: The clinical use of ranitidine. Symposium series 5. Oxford: The Medicine Publishing Foundation, 1982. 